\title{
A Critique of Meinongian Assumptions
}

\author{
Arnaud Dewalque
}

\section{Summary}

This article argues that Meinong's analysis of assumption, while exploring the variety of phenomenological primitives in a more promising way than Brentano did, nevertheless fails to adequately account for (i) the noncommittal character of assumptive attitudes and (ii) the difference between assumptive and other neighbouring attitudes. Section 1 outlines an overall framework for the philosophical analysis of assumptions and cognitive attitudes. Section 2 gives an overview of Brentano's analysis of cognitive attitudes and some difficulties thereof. Section 3 offers a critical examination of Meinong's rival analysis. Eventually, Section 4 suggests an alternative route, according to which assumptive attitudes are best analysed in taking entertaining that $p$ as a phenomenological primitive besides affirming that $p$.

\section{Introduction}

It is sometimes held that cognitive states - believing, thinking, understanding, and the like - exhibit a kind of proprietary and distinctive phenomenology, that there is "something it is like" to be in a cognitive state or to undergo a cognitive experience. Over the two last decades or so, this claim has been subject to lively discussions. Typical cases at issue involve what it is like to understand the meaning of a spoken or written sentence (as opposed to merely hearing or reading the sentence without understanding it), or what it is like to know that a proposition is true. Part of the debate evolves around the alleged cogency of pro and con arguments regarding the existence and reducibility of cognitive phenomenology. Taking for granted that there is something it is like to understand a sentence, is the understanding experience (say) reducible to an auditory experience plus some kind of mental imagery and/or emotional 
ingredient? ${ }^{1}$ At the same time, the question as to what exactly is the character of cognitive experiences and how to give the best description thereof became a hot spot again after a period of neglect. ${ }^{2}$

Both aspects of the debate have historical antecedents. On the one hand, the question concerning the existence and irreducibility of cognitive phenomenology is not unlike the old controversy on "imageless thoughts". ${ }^{3}$ On the other, the question concerning the character of cognitive experiences is not alien to the phenomenological analyses offered by Brentano and his students. Even though their considerations on judgemental acts are not conducted in terms of phenomenal character, there are reasons to think that classical phenomenologists in the Brentanian tradition simply take it for granted that there is (what is called today) a distinctive phenomenology of judging and neighbouring cognitive attitudes. ${ }^{4}$ At stake for Brentano and his followers simply is the description of the phenomenological character of subjective experiences, broadly understood.

This paper locates Meinong's theory of assumptions within the theoretical space opened up by the systematic description of cognitive experiences. More pointedly, it focuses on the character of assumptive attitudes. The chief issue is how to best describe assumptive attitudes. I argue that Meinong's analysis of assumption, while exploring the variety of phenomenological primitives (affirming that $p$ as distinct from believing that $p$ ) in a more promising way than Brentano did, nevertheless fails to adequately account for (i) the noncommittal character of assumptive attitudes and (ii) the difference between assumptive and other neighbouring attitudes. My plan is as follows. Section 1 outlines an overall framework for the philosophical analysis of cognitive attitudes. Section 2 gives an overview of Brentano's analysis and some difficulties thereof. Section 3 offers a critical examination of Meinong's competing view. And Section 4 suggests an alternative route, according to which assumptive attitudes are best analysed in taking entertaining that $p$ as a phenomenological primitive besides affirming that p.

\footnotetext{
${ }^{1}$ See Bayne / Montague eds. 2014.

${ }^{2}$ See Breyer / Gutland eds. 2015.

${ }^{3}$ Dewalque 2017.

${ }^{4}$ See, e.g., Smith 2015, p. 64: "In the phenomenological tradition, since Brentano and Husserl, it seems widely assumed that every conscious experience has a distinctive type of phenomenal or phenomenological character." The reason it is so probably has to do with the fact that, for Brentano and Husserl, intentionality and phenomenality are not disconnected from one another (Kriegel 2013b, p. 2). Yet, I won't say more about that here.
} 


\section{In Search for Phenomenological Primitives}

In this first section I want to suggest that Brentano's and Meinong's analyses of cognitive attitudes are best understood as part and parcel of an overall research programme which aims at discovering phenomenologically primitive notions - or phenomenological primitives for short. This programme rests upon a number of background claims. What follows is an attempt to make those claims explicit and to formulate them in a way that fits the present-day research situation.

First, Brentano's theory of judgement and Meinong's theory of assumption take place within the framework of a "descriptive analysis" of mental phenomena. ${ }^{5}$ Their approach to cognitive attitudes is phenomenological in the sense that it aims at capturing distinctions that are phenomenally manifest to the subject. It is descriptive in the sense that it purports to answer questions of the form What is $P$ ? And it is analytic in the sense that answering such questions requires one to paraphrase or recast some notions in terms of others.

Historically speaking, this combination of phenomenological description and conceptual analysis is at the heart of Brentano's programme. ${ }^{6}$

Second, central to this programme is the claim that phenomenal distinctions are not exhausted by distinct ways of representing the world, or "contentual distinctions." They first and foremost involve attitudinal distinctions. Brentano and Marty emphatically insist that any satisfying description of mental phenomena has to deal with distinct "relational modes of the soul" (Beziehungsweise der Seele) or distinct "modes of the intentional relation" (Modi der intentionalen Beziehung). ${ }^{7}$ The basic assumption is that (i) there are different attitudes toward the same object represented in the same way, and (ii) those attitudes are phenomenally manifest to the subject. For example, believing that today will be a sunny day differs from hoping that today will be a sunny day, and this attitudinal difference is taken to be phenomenally manifest to the subject. If an interpretation of Brentano and Meinong along those lines is correct, then it is probably not unfair to say that their respective analyses of cognitive attitudes aim at capturing what is sometimes called today the phenomenology of attitude type. $^{8}$

Third, what are cognitive attitudes? According to a prima facie negative characterisation, cognitive attitudes are mental attitudes which are neither sensory nor algedonic (pain/pleasure) nor emotional. ${ }^{9}$ Most of the time, cognitive

\footnotetext{
${ }^{5}$ See., e.g., Brentano 1995a.

${ }^{6}$ See, e.g., Dewalque 2014; Röck 2017.

${ }^{7}$ See, e.g., Marty 1906.

${ }^{8}$ Horgan / Tienson 2002, 522-23.

9 See, e.g., Twardowski 2014, p. 134: “'Thinking' in the broader sense encompasses all mental functions and activities, without exception, which do not belong to the sphere of
} 
attitudes may be constructed as attitudes towards a proposition $p$, or propositional attitudes. Yet, the question as to whether every cognitive attitude is propositional cannot be settled a priori and should be left unanswered at the outset. For the sake of convenience, however, I'll stick in this article to propositional constructions of the form " $\varphi$-ing that $p$." A list of cognitive attitudes would include (but would not be limited to) the following: thinking that $p$, believing that $p$, judging that $p$, entertaining that $p$, supposing that $p$, knowing that $p$, suspecting that $p$, wondering whether $p$, doubting that $p$, etc.

Fourth, I take it that the analytic description of such cognitive attitudes essentially is a matter of how the relevant notions are connected with each other. One basic assumption behind this research programme is that mental verbs like those forming the aforementioned list make up a web of interconnected notions. These notions are interconnected in the sense that some of them are likely to be descriptively analysed in terms of some others. This is where the concept of phenomenological primitive enters the picture. A phenomenological primitive is a notion which is part of the understanding of another, less fundamental notion, and which cannot in turn be understood in terms of other, more fundamental notions. In sum, phenomenological primitives (i) do not admit of any further descriptive analysis - i.e., cannot be paraphrased - and (ii) have a phenomenal import in the sense that they capture a property $P$ whose presence or absence is phenomenally manifest to the subject. At stake is not only the number of primitives that are needed in order to account for cognitive attitudes, but also the nature thereof and their place in our overall web of phenomenal attitudinal notions. Reduced cognitive attitudes may be said to be grounded on more basic notions and, ultimately, on phenomenological primitives. ${ }^{10}$ Much of what I have to say in this article will be dedicated to the exploration of such grounding connections.

However sketchy, those indications suffice when it comes to get a grip on what is involved in the philosophical project of describing cognitive attitudes. At first sight, the agenda for this research programme is to answer these two questions:

Q1 In virtue of what are cognitive attitudes distinguished from one another?

Q2 Which cognitive notions are derived, and which are conceptually primitive?

In my view, Meinong's theory of assumptions may be seen as a pioneering contribution to this research programme. Yet, since Meinong's classification of

perception, or to the emotional-volitional sphere, regardless of whether thinking is concrete or abstract."

${ }^{10}$ For a similar view, see Kriegel 2015b. 
mental phenomena is a critical continuation of Brentano's, I think it advisable to start with a brief examination of Brentano's own list of phenomenological primitives. This is the business of the next section.

\section{Brentanian Primitives}

In the 1874 Psychology from an Empirical Standpoint (hereafter PES), Brentano wants to offer a "natural classification" or taxonomy of mental phenomena. This taxonomy "must unite into a single class objects closely related by nature, and it must separate into different classes objects which are relatively distant by nature". ${ }^{11}$

It is common knowledge that, on Brentano's view, the most adequate classification of mental phenomena is into presentations, judgements, and loveand-hate phenomena. This tripartite classification shows a number of interesting characteristics. To begin with, it may be said to be purely psychological, in the sense that it is based on (what Brentano takes to be) intrinsic features of mental phenomena rather than extrinsic factors. Now in PES Brentano holds that each type of mental phenomenon has its own, intrinsic way of being intentionally related to something. One way of capturing this idea is to say that, while all mental phenomena are intentional, each fundamental class of mental phenomena is characterised by an "entirely new" mode of intentionality. ${ }^{12}$ To give but a trivial example, suppose you think of your favourite ice cream flavour, which happens to be Raspberry Ripple, and then come to judge that Raspberry Ripple is your favourite ice cream flavour. Brentano would say that, when moving from thinking of (understood as a nominal and noncommittal attitude) to judging that (which is committal), you experience an entirely new attitude towards the content of your mental act, to the effect that your favourite ice cream flavour is not only presented but judged about. By contrast with presentations, judgements are committal attitudes. Now an analogous change of intentional attitude occurs, Brentano would go on, when you do not only judge that Raspberry Ripple is your favourite ice cream flavour but also feel an interest for it and desire to eat it. In respect to presentation and judgement, interest is an entirely new way of being intentionally related to something. Feeling an interest for something is committal, too, but not in the same sense as judging: It is a different attitude altogether. In sum, Brentano's classification is attitudinal. As George Stout aptly remarks, "differences in the nature of the object are from this

\footnotetext{
${ }^{11}$ Brentano 1995b, p. 194. I have examined the "natural" character of Brentano's classification elsewhere. See Dewalque 2018 (on which the three following paragraphs are based).

${ }^{12}$ See, e.g., Brentano 1995b, 201, etc.
} 
point of view irrelevant. Only the attitude or posture of consciousness towards objects is to be taken into account". ${ }^{13}$

A second interesting aspect of Brentano's classification is that his three classes are ordered in virtue of one-sided dependence relations obtaining between the related phenomena. Presentations somehow underlie all mental phenomena, while judgements presuppose presentations and interests presuppose presentations and judgements. True, in 1874, Brentano holds the view that emotions or interests are all-pervading in human mental life. Presentations, most of the time if not always, arouse a judgemental and emotional response; they are only a "part" of more complicated mental phenomena. Still, Brentano would argue, it is not impossible for you to have a presentation of a Raspberry Ripple ice cream without judging anything about it, whereas it is impossible for you to judge that Raspberry Ripple is your favourite ice cream flavour without thinking of it or having a presentation of it. By analogy, while it is not impossible to judge that something is the case without experiencing any interest or emotion, it is impossible to experience an interest for something without judging that something is the case.

A third aspect of Brentano's classification as that it is conceived of as being complete. However lush one's mental life may be, Brentano argues that, as far as modes of intentionality are concerned, all mental phenomena may be accounted for in terms of presentations, judgements, interests, and combinations thereof. Admittedly, some further distinctions are fairly important, too. Think, for example, of the distinctions between affirmative and negative judgements, self-evident and blind judgements, direct and oblique presentations, love and preference, etc. However, as far as such distinctions correspond to subspecies of the above-mentioned mental species, Brentano takes them to be "non-fundamental". ${ }^{14}$ The reason why presentations, judgements, and interests exhaust the number of fundamental classes is that mental phenomena, in Brentano's view, exhibit "no more and no less than a threefold fundamental difference in their reference to a content". ${ }^{15}$

Now my present concern is not with Brentano's classification, but with the conceptual relations he advocates when describing judgemental and presentational attitudes. ${ }^{16}$ Importantly, it is worth emphasising that the notions of judgement and presentation are not phenomenologically primitive. Brentano

\footnotetext{
13 Stout 1896, p. 40.

${ }^{14}$ See Kriegel 2017, p. 100-101.

${ }^{15}$ Brentano 1995b, p. 264; my emphasis.

${ }^{16}$ Although presentational attitudes cannot be said to be cognitive in the strict sense of the term, since they are not properly concerned with truth and falsity, I shall include them into the picture, for Brentano maintains that they ground judgemental and understanding attitudes, which clearly have a cognitive import.
} 
uses the notion of "judgement" whenever something is acknowledged as correct or rejected as incorrect, which suggests that the primitives at play here are accepting (or acknowledging) and rejecting. And he uses the notion of "presentation" (Vorstellung) whenever something "appears" to the subject in the broadest sense of the term or is merely "given in consciousness" without there being any judgemental or emotional attitude involved. ${ }^{17}$ In other words, everything one is aware of may be said to be presented in Brentano's sense. This suggests that the primitive notion here is that of being aware of something or being appeared to by something.

On Brentano's view, judging and having a presentation, albeit non-primitive, nevertheless stand in a grounding relation to further cognitive notions. While the notion of judging plays a central role in Brentano's analysis of knowing that $p$, his notion of presentation plays a central role in his analysis of understanding attitudes. As regards the first point, it is plain that Brentano, in line with Aristotle and the Aristotelian tradition, endorses a judgemental account of knowing: "Knowledge is to be found in judgement and makes up the perfection of the latter". ${ }^{18}$ By contrast, Brentano's account of understanding attitudes is less easy to pin down. Yet, in PES, he clearly argues that understanding some linguistic expression is best analysed in terms of having some presentations: "When I hear and understand a word that names something, I have a presentation of what that word designates; and generally speaking the purpose of such words is to evoke presentations". ${ }^{19}$

Accordingly, Brentano's analysis of cognitive attitudes may be summarised by means of the following paraphrases, which I shall label B0-B3:

(B0) $S$ has a presentation of $A$ iff $S$ is appeared to by $A .^{20}$

(B1) $S$ judges that $A$ iff $S$ has-a-presentation-of-and-accepts $A$ or $S$ has-apresentation-of-and-rejects $A$.

(B2) $S$ understands a linguistic expression $E$ iff $S$ has a presentation of what is meant by $\mathrm{E}$.

(B3) $S$ knows that $p$ iff (i) $S$ judges that $p$ and (ii) S's judging that $p$ is selfevident to $\mathrm{S}$.

No need to say, further analyses might be added to B0-B3.

\footnotetext{
${ }^{17}$ Brentano 1995b, p. 81, 198, 1956, p. 32.

${ }^{18}$ Brentano Ms. EL 80, p. 12.986(4), 1956, p. 23.

${ }^{19}$ Brentano 1995b, p. 198.

${ }^{20} \mathrm{BO}$ is, so to speak, the "zero level" of cognition, since in Brentano's eyes "being appeared to by $A$ " is noncommittal with respect to $A$ and, therefore, is not truthassessable. It is, however, prerequisite for any cognitive attitude directed at $A$.
} 
Brentano's account provides us with the following answers to our opening questions. With respect to $Q 2$, attitudes which are reductively analysed stand on the left side of the iff-sign, while phenomenal primitives stand on the right side. Therefore, having a presentation, judging and knowing are reducible, nonprimitive notions, while being-appeared-to, acknowledging, rejecting, and selfevidence are considered phenomenal primitives. With respect to Q1, Brentano holds that those distinctions are attitudinal only. Presentation and judgement, for example, clearly are "two entirely different ways of being conscious of an object". ${ }^{21}$ Even though it is tempting to introduce some differences at the level of content, such differences are a matter of irrelevance when it comes to analysing the related attitudinal concepts. A presentation is a presentation in exactly the same sense no matter whether it is a presentation of a simple or complex content; and a judgement is a judgement in exactly the same sense no matter whether it has a propositional content $(p)$ or a merely nominal content (A). Again, the criterion for such attitudinal distinctions is what Brentano will call, later on, unilateral separability: even if it is not possible for $S$ to judge that $p$ without having a presentation of $p$, it is possible for $\mathrm{S}$ to have a presentation of something without judging. As shown in B1, having a presentation of something is considered a built-in feature of any judgemental attitude.

Before turning to Meinong's own analyses, I want to briefly review some difficulties with Brentano's analyses. One first difficulty (call it Difficulty 2.1) is with phenomenal complexity. On B1, judging is not phenomenally simple, but phenomenally structured. How are we to conceive of such a phenomenal structure? One first option is to say that the new attitude is somehow added to the previous one. This interpretation is supported by the claim that judging has presenting as a "psychological prerequisite." Another option is to say that the new attitude is a modification of the previous one. This interpretation is supported by the thought that $S$ cannot have a presentation of $A$ and accept or reject $A$ at the same time. This is what Husserl notices. It seems impossible, Husserl argues, to merely have a presentation of something and simultaneously judge about exactly the same thing in exactly the same respect. Presentational attitude, which is noncommittal, and judgemental attitude, which is committal, are incompatible..$^{22}$ I think this difficulty is a serious one. For the present purpose, however, there is no need to settle this issue. We can stay neutral on how to best conceive of the phenomenal structure.

A second difficulty (Difficulty 2.2) is connected to B1. Interestingly, B1 is disjunctive: Brentano takes it that judging is either accepting or rejecting. In other words, there are "two attitudinal phenomenal features" of judging rather

${ }^{21}$ Brentano 1995b, p. 201; Stout 1896, p. 40.

${ }^{22}$ Husserl 2002, p. 110. 
than one single attitudinal feature of truth-commitment. ${ }^{23}$ On the face of it, it is hard to see how this analysis might provide us with a unified understanding of what judging is. Furthermore, it might be objected that acknowledging and rejecting are not phenomenal primitives, indeed that various phenomena are likely to be understood under those notions, which subsequently require some clarification. For example, it may be urged that judging is neither assessing-astrue nor assenting to a judgement - yet, insofar as those three notions (judging, assessing-as-true, assenting to a judgement) are likely to be captured by the notion of accepting, the latter turns out to be equivocal (Reinach 1989b; Dewalque 2016). The same holds true, a fortiori, with respect to affirming and believing, two notions arguably encapsulated within Brentano's notion of acceptance. Therefore, it may be objected that Brentano's analysis is too coarse-grained and that further distinctions are needed.

A third difficulty (Difficulty 2.3) with Brentano's account of cognitive attitudes has to do with B2 and, more pointedly, with the understanding of a sentence. Let us take for granted that understanding a word (e.g., $<$ tree $>,<$ Albornoz fortress $>$ ) amounts to having a presentation of something, as stated in B2. The question arises as to what it is to understand an affirmative or negative sentence ( $<$ this tree is an oak >, <Albornoz fortress is the highest point of Urbino $>$ ). It cannot be having a presentation corresponding to each word, for there is no presentation for each and every word (e.g., "is", which is a synsemantical term), and it cannot be judging that $p$, otherwise it would be impossible to understand a false proposition without affirming it and thus making an error. Hence the question arises as to what kind of attitude is the understanding of a sentence.

Meinong's theory of assumption may be seen as an attempt of dealing with Difficulties 2.2 and 2.3.

\section{Meinongian Primitives}

It certainly is natural to see Meinong's treatise on assumptions ${ }^{24}$ as part of a broader project, namely, that of improving Brentano's classification of mental phenomena. Very roughly, Meinong replaces Brentano's tripartite division by a twofold division into cognitive and emotional phenomena, separates presentations and thoughts as two subclasses of cognitive phenomena, and

\footnotetext{
${ }^{23}$ Kriegel 2015 a, p. 33.

${ }^{24}$ Meinong 1902, 1910, 1977.
} 
introduces assumptions as a subclass of thoughts on a par with judgements. ${ }^{25}$ Meinong's classification may be illustrated by the following diagram:

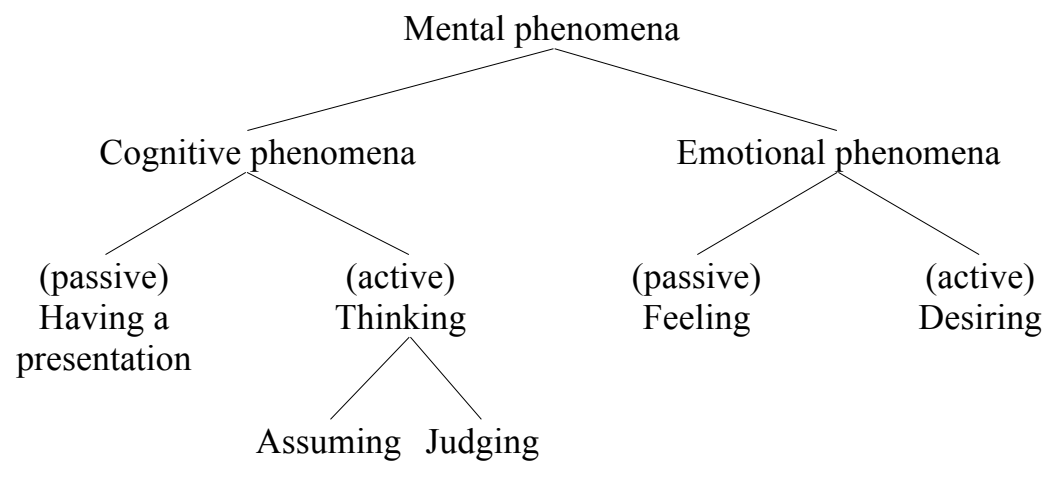

Fig. 1. Meinong's Classification of Mental Phenomena

In his treatise on assumptions, however, Meinong's goal was not just to demonstrate that assumption is a fundamental attitude between presentation and judgement. It was to show that the notion of assuming, first, is part of the analysans of, and plays the role of a grounding notion for, a number of cognitive attitudes, and next, that assuming is a non-primitive attitude which nevertheless cannot be analysed in terms of judgement and presentation. Let's call the first aspect the Centrality of assumptive attitudes, and the second one the Specificity of assumptive attitudes.

\section{Centrality}

The notion of assuming that $p$, although it is not itself a phenomenological primitive, is implicit in a number of cognitive attitudes, hence is required for the descriptive analysis of the latters.

\section{Specificity}

Assuming that $p$, albeit non-primitive, is a sui generis cognitive attitude which is not reducible to having a presentation, judging, or a combination thereof.

\footnotetext{
${ }^{25}$ For a critical discussion, see Marty 1906. Interestingly, Meinong's modifications go hand in hand with the endorsement of a dichotomy method: Mental phenomena are divided into emotional and non-emotional (i.e., cognitive), emotional phenomena are divided into passive (feeling) and active (desires), and so are cognitive phenomena (presentations are passive, thoughts are active, viz. involve an affirmative or negative component). The resulting classification is exposed in Höfler 1894, p. 29 ff., 1930, p. 102 $\mathrm{ff}$. The method of dichotomous division usually is traced back to Aristotle, who explicitly rejected it for biological species, one reason being that dichotomous divisions lead to unnatural groups (Richards 2010, p. 21-22).
} 
Centrality implies that it is not possible to adequately describe or analyse a number of cognitive experiences (analysanda) without including the notion of assuming that $p$ in the analysans. One way of reconstructing Meinong's argument for Centrality is by means of his notion of "objective" (Objektiv) Meinong's name for a state of affairs. It runs as follows:

P1 If $S$ apprehends an objective, then $S$ judges that $p$ or $S$ assumes that $p$.

P2 There are some and, indeed, many states $x, y, z, \ldots$ such as, when $S$ is in $\mathrm{x}, \mathrm{y}, \mathrm{z}, \ldots, \mathrm{S}$ apprehends an objective and $\mathrm{S}$ doesn't judge that $p$.

Therefore,

C there are some and, indeed, many states $\mathrm{x}, \mathrm{y}, \mathrm{z}, \ldots$ such as, when $\mathrm{S}$ is in $\mathrm{x}$, $\mathrm{y}, \mathrm{z}, \ldots, \mathrm{S}$ assumes that $p$.

Thus reconstructed, the argument is valid. P1 shows a crucial departure from Brentano's analyses. Recall that, for Brentano, the nature of the content (whether nominal or propositional) does not put any constraint whatsoever on the nature of the related attitude: I can have a presentation of $\angle A>, \angle A$ which is $B>$ or $<A$ which is not $B>$. Similarly, I can accept that $<A$ is $B>$ or I can accept $<A>$ itself, say, in the case of an existential judgement ("A is"). When it comes to determining the attitudinal character of the act, the content of the act is a matter of indifference. $\mathrm{P} 1$ breaks with this conception by stating that, whenever what is apprehended is not a single object, but an objective, the apprehending act must be a judgement or an assumption. Meinong's rationale for adopting P1 runs as follows. An objective is a higher-order object ("superiorus") which is founded upon lower-level objects ("inferiora"). Now for founded objects to be apprehended, the corresponding thought has to be actively produced by the mind. Therefore, apprehending an objective requires some judgemental or assumptive activity. I won't discuss this argument here. Suffice it to note that it presupposes the theory of production which has been elaborated on by Meinong and some of his heirs. ${ }^{26}$

Now Meinong contends that many mental states fall in the scope of P2: meaning that $p$, understanding that $p$, lying, wondering, etc. All those states require one to actively apprehend an objective without judging that $p .{ }^{27}$ But how are we to account for the so-called "activity" involved here? And in what sense, exactly, does it differ from judging that $p$ ? Meinong's answer is straightforward: it is a convictionless affirmation or negation, and this convictionless affirmation or negation precisely is what is called here an assumption. We arrive at this

\footnotetext{
${ }^{26}$ See, e.g., Höfler 1894; Witasek 1908; etc.

${ }^{27}$ Judging is but one kind of "intellectual work" or intellectual "activity" among others. See already Höfler 1894, p. 55 ff.
} 
notion of assumption, Meinong remarks, when one notices that the notion of affirming that $p$ and the notion of being convinced that $p$ do not stand in the determinate-determinable relationship. Affirming that $p$ is not a determinate of being convinced that $p$. On the contrary, Meinong argues, it is quite possible for a subject $S$ to affirm that $p$ without believing or being convinced that $p .^{28}$ This indeed happens very often. For example when $\mathrm{S}$ lies to someone, $\mathrm{S}$ affirms something she does not believe or denies something she does believe. Similarly, Meinong goes on, when $\mathrm{S}$ understands (the thought) that $p, \mathrm{~S}$ does not need to believe that $p$. S merely needs to think that $p$, where thinking that $p$ is tantamount to forming the related affirmation or negation "in a neutral way", namely: without forming the related belief or disbelief.

We now are in a position to give a rough picture of Meinong's analysis of cognitive attitudes. On Meinong's view, any nominal content may be apprehended by means of an act of presentation, where an act of presentation of $A$ is a passive apprehension of $A$. It is passive in the sense that no production of articulated content is involved. By contrast, thinking that $p$ is required for a subject $S$ to apprehend the corresponding objective. Now thinking that $p$ comes in two forms: either $S$ judges that $p$, to the effect that $S$ affirms-and-believes that $p$ (or denies-and-disbelieves that $p$ ), or $S$ assumes that $p$, to the effect that $S$ affirms that $p$ without believing that $p$ (or denies that $p$ without disbelieving that $p)$. Accordingly, the 'affirming' or 'denying' component - or, as Meinong says, the yes-no opposition - is common to both judgement and assumption. The difference between the two merely is that, in the case of assumption, the belief component lacks entirely - or, in some cases, is merely reproduced imaginatively. ${ }^{29}$ To put it differently, Meinong's analysis rests upon the idea of a privative contrast between judgement and assumption: the former does, while the latter does not, exhibit a belief component or an "aspect of conviction" (Überzeugungsmoment). As a result, Meinong's analyses suggest that the following equivalences are true:

(M0) S has a presentation of $A$ iff $S$ passively apprehends $A$.

\footnotetext{
28 "I would have always thought it obvious that any conviction has to be affirmative or negative, but I would have never expected to find affirmation or negation in any case where conviction was lacking. That this is neverthless possible and, indeed, anything but rare in its realization - this point, along with the consequences of it, constitutes about the most important thing to be shown by the following discussions" (Meinong 1910, p. 4, 1977 , p. 4, 1976, p. 11).

${ }^{29}$ Meinong 1968, p. 333. This does not mean, of course, that in assumption an act of affirmation is combined with an act of disbelief: rather, the affirmation comes alone, without being accompanied by any "conviction" (Überzeugung). An assumption, in Meinong's view, is an affirmation (or a negation) which is disconnected from belief (or disbelief).
} 
(M1) S thinks that $p$ (or actively apprehends $p$ ) iff $S$ judges that $p$ or $S$ assumes that $p$.

(M2) $S$ judges that $p$ iff $S$ affirms-and-believes that $p$ or $S$ denies-anddisbelieves that $p$.

(M3) $S$ assumes that $p$ iff $S$ affirms-without-believing that $p$ or $S$ denies-withoutdisbelieving that $p$.

Moreover, as suggested by Centrality, assuming that $p$ is a necessary ingredient of further cognitive attitudes. In Über Annahmen, Meinong mentions at least the following cases:

(M4) $S$ means that $p$ iff (i) $S$ utters a sentence expressing $p$ and (ii) $S$ assumes that $p$.

(M5) $\mathrm{S}$ understands that $p$ iff (i) $\mathrm{S}$ has a sensory presentation of a sentence expressing $p$ and (ii) $S$ assumes that $p .^{30}$

(M6) $\mathrm{S}$ lies iff (i) $\mathrm{S}$ means that $p$ and (ii) $\mathrm{S}$ disbelieves that $p$.

(M7) $S$ wonders whether $p$ iff (i) $S$ assumes that $p$ and (ii) $S$ desires to know whether $p$.

Let me take stock. Meinong's list of phenomenological non-primitives includes having a presentation, judging, assuming, meaning, understanding, lying, wondering, and thinking. His list of phenomenological primitives includes passively apprehending, affirming, denying, believing, disbelieving, and uttering. Both lists are open. Moreover, like Brentano, Meinong takes it that judging and assuming presuppose having a presentation. Unlike Brentano, however, he offers a more fine-grained analysis of judging, for he distinguishes between two components that are equally present in judging: the affirming or denying component, and the belief component ("conviction"). This distinction, it may be argued, makes Meinong's analysis more promising than Brentano's, indeed puts him in a better position when it comes to avoiding Difficulty 2.2. The belief component and the assertion component (affirmation or negation) are clearly distinguished from one another.

That said, it is a pending question whether M0-M7 adequately account for the phenomena at issue and offer a consistent analysis of cognitive experiences. $A$ full-blown critical discussion should probably consider each equivalence (MOM7) in turn. However, rather than engaging into detailed case studies, I shall confine myself to mention five general difficulties.

\footnotetext{
${ }^{30}$ See also Russell 1910, 1951, p. 159, 2004, p. 209: "When we can suppose that $A$ loves $B$, we 'understand the proposition' $A$ loves $B$. Thus we often understand a proposition in cases where we have not enough knowledge to make a judgement".
} 
First of all (Difficulty 3.1), it may be argued, against M3, that assuming does not show the kind of attitudinal oppositionality judgemental attitudes exhibit, namely a yes-no attitude which has to be distinguished from the contentual opposition between $p$ and not- $p$. If I am not mistaken, there is no sharp distinction between an attitudinal and a contentual opposition in Meinong's analyses. Both sides are thought of as closely connected. This ambivalent status of affirmation and negation becomes still more obvious in Witasek's psychology. When the content of a judgement is "touched" (berührt) by the affirming or denying act, Witasek writes, a "quasi-contentual aspect" (quasi-inhaltliches Moment) is added to the overall mental phenomenon, to the effect that the content is "complicated with the yes or no" ${ }^{31}$ In other words, with the attitudinal oppositionality, some oppositionality is introduced in the content of the act of judging. Yet, even if one takes this description for granted, it is questionable that something similar occurs in the case of assumptions. Are there really negative assumptive attitudes? Can you negatively assume that $p$ ? Does that even make sense? It seems to me that the answer is no. Now if we stick to Brentano's (and Meinong's) claim that judging is either accepting or rejecting, the absence of negative assumptions arguably creates a gap between assuming and judging, and speaks for the view that assuming is a non-oppositional attitude like presenting or asserting. Just like a negative assertion is the assertion of something negative, a negative assumption seems to be best construed as the assumption of something negative..$^{32}$ This is why Russell, for example, leaned towards an analysis of assumptions in terms of presentations, for presentations, too, are non-assertive attitudes which lack any oppositional character. Be that as it may, it is essential to distinguish between contentual similarity and attitudinal similarity. Russell write: "The greater likeness of assumptions to judgments, we shall conclude, is derived from the identity of their objects and the close similarity of their contents; but in regard to the act, assumptions are to be classed with presentations, being merely the presentations of objects of a certain kind". ${ }^{33}$ From a merely attitudinal point of view, assuming that $p$ is neutral or noncommittal.

\footnotetext{
${ }^{31}$ Witasek 1908, p. 281.

${ }^{32}$ After all, this is also what Witasek suggests, willy nilly, when he writes that what assuming that $p$ and judging that $p$ have in common is (i) the content $\langle p>$ and (ii) the "quasi-contentual aspect" of affirmation and negation (Witasek 1908, p. 311). My proposal is to drop the "quasi-" prefixe and to say that the affirmative or negative aspect present in assumption is contentual through and through, to the effect that a negative assumption actually is the assumption of something negative - full stop.

${ }^{33}$ Russell 1904, p. 352, my emphasis. Later on, after Meinong's reply in the second edition of Über Annahmen, Russell moved closer to Meinong's position and agreed that assuming or supposing is a sui generis attitude (see Russell 1910, 1951, p. 159, 2004, p. 209).
} 
A further worry (Difficulty 3.2) is with the incompatibility between assuming that $p$ and judging that $p$. Suppose you are reading and understanding a scientific text but have no idea whether what you are reading is true or not. In that case, Meinong would say, you are merely assuming the content of the text without performing any judgement about it. Then, when you take stance on what you have read, you switch from assumption to judgement. In this scenario, the assumption just is a preliminary attitude - the attitude of thinking without judging - you are forced to adopt as long as you are not in the position of taking stance. Now suppose you are asked to consider a counterfactual hypothesis, which you know is false. In that case, the situation is different. It is plain that you can assume something you take to be false. The case of counterfactual hypotheses suggests that $S$ 's assuming that $p$ is compatible with S's disbelieving that $p$. For instance, you can be asked to assume that $<2+2=5>$ even if you know (judge with self-evidence) that it is false, hence reject it. Now, on Meinong's analysis, the situation would be this: $\mathrm{S}$ assumes, that is affirms-without-believing that $p$ and $S$ judges to be false, that is, denies-and-disbelieves that $p$. Thus, $S$ affirms and denies the same propositional content at the same time in the same respect. Now affirming that $p$ and denying that $p$ are incompatible, indeed contradictory attitudes. Therefore, this way of understanding assumptions fails to account for the compatibility between assuming and judging. ${ }^{34}$

It might be replied that this objection does not take into account the fact that Meinong replaced Brentano's notions of acceptance/rejection by the notions of affirming/denying. The latters presumably refer to a mere attitudinal component (not per se a full-blown attitude), which might also be characterised as positing/non-positing something. Now it may be argued that positing/nonpositing $p$ is quite compatible with the acceptance/rejection of $p$, to the effect that the compatibility problem just vanishes. There is no incompatibility between rejecting-as-incorrect that $<2+2=5>$ and assuming or positing-without-believing that $<2+2=5>$. The case for Meinong's analysis is neatly put by Sébastien Richard: "It is indeed impossible to accept and reject the same matter at the same time and in the same respect, but assumption is not so much about acceptance and rejection than position - the putting of a case". ${ }^{35}$

One way of putting this idea is to conceive of the phenomenal structure of judgements and assumptions in terms of modification, rather than in terms of addition: the affirmation (resp., negation) is modified by the presence or absence of belief component, to the effect that the word "affirmation" does not denote the same attitudinal component in judging that $p$ and assuming that $p$. However,

\footnotetext{
${ }^{34}$ Marty 1906, p. 21-23.

${ }^{35}$ Richard 2017, p. 233. The idea that assuming is best understood as das Setzen eines Falles may be traced back to Frege 1891, p. 21. See also Meinong 1977, p. 6, fn. 1.
} 
it is far from being clear whether this move really enables Meinong to resist the objection. The problem comes from the fact that Meinong precisely conceives of the positing/non-positing as a common ingredient in judgement and assumption. This common affirmative or negative component, which is supposed to be present both in assumption and in judgement, is the source of a serious difficulty, for it blocks any attempt of understanding "affirming" in two different ways. ${ }^{36}$ A negative judgement that $p$ is supposed to be an act of denying-and-disbelieving that $p$, while an affirmative assumption that $p$ is supposed to be an act of affirming-without-believing that $p$, and the two clearly seem mutually exclusive. Again, this suggests that a more neutral attitude than the yes-no attitude is needed if we are to account for such a compatibility.

A similar issue (Difficulty 3.3.) is raised as soon as one has to deal with multiple assumptions. The situation is described by Brentano in the 1911 appendix to PES: "As Meinong uses [the notion of assumption or supposition], we could often suppose two contradictory things at the same time, as for example when we say, 'Locke says that Descartes is mistaken in teaching that there are innate ideas.' For in this case we would be supposing that someone is mistaken when he teaches that there are innate ideas, and supposing that there are innate ideas, all at the same time". ${ }^{37}$ The only way out would be to acknowledge still another sui generis attitude which would be to the assumption what the assumption is to the judgement. I won't say more about that, although this difficulty is maybe less peripheral than it may seem at first sight.

A fourth difficulty (Difficulty 3.4) is tied to what I shall call the problem of converse separability. Contrary to what Meinong wrotes, it may be objected that affirming-without-believing that $p$ is impossible. The idea would be this. Meinong's account takes the phenomenology of affirming wrong, for "every

\footnotetext{
${ }^{36}$ Note that this already was the core of Marty's famous objection against Specificity an objection which employs Aristotle's and Brentano's method of aporia. Marty's argument runs as follows (Marty 1906, 1908, p. 245): 1) there are only two ways of understanding assumptions as sui generis attitudes: either assumptions and judgements are different genera of mental attitudes or they are species of the same genus; 2 ) if assumptions and judgements share the same affirmative or negative component, then they cannot possibly be different genera; now 3 ) they share the same affirmative or negative component (according to Meinong); therefore, 4) they cannot possibly be different genera; 5) if the only difference between them is that assumptions lack of belief component, then they cannot be different species of the same genus, for different species are distinguished from one another by a positive rather than a merely privative contrast; now 6) the only difference between assumptions and judgements (according to Meinong) is that assumptions lack of belief component; therefore, 7) they cannot be different species of the same genus; hence 8) none of the ways of understanding assumptions as sui generis attitudes works. For a more thorough reconstruction of the Marty-Meinong controversy, see Richard 2017.

${ }^{37}$ Brentano 1995b, p. 285.
} 
affirmation rests upon a conviction" ${ }^{38}$ while "a conviction may exist without any affirmation". ${ }^{39}$ For example, on Reinach's account, it seems that a lie doesn't involve an affirmation properly speaking, but only an apparent or modified affirmation: at the psychological level, the liar doesn't affirm anything, he merely simulates an affirmation. The same might be said of the actor who is playing a role on the theater stage. On Meinong's view, the actor makes affirmations which are assumptions: he affirms-without-believing, for example, that he is King Lear. The question at issue is whether this affirmation is an affirmation in the plain sense of the term. My suggestion is that it is best understood as a simulated affirmation. But a simulated affirmation is not an affirmation, for "simulated" is here used in a modifying way (in Brentano's sense). If this suggestion is correct, then, pace Meinong, an assumption is not and cannot be an actual affirmation. It is only the appearance of an affirmation.

Eventually (Difficulty 3.5), it may be objected that Meinong's analyses, by relying on Centrality, fail to account for a number of descriptive or phenomenological differences. For example, it may be argued that there is some phenomenological difference between assuming in the sense of testing a hypothesis and understanding - disregarding the fact that, in the case of understanding, one hears or reads a sentence. For one part, when one performs an assumption in order to reach a certain conclusion, the overall phenomenology arguably involves some interest or conative ingredient, to the effect that one desires to reach a conclusion. Whether a similar conative ingredient is integral to the understanding experience is questionable. Moreover, it is true that, in order to understand a sentence, I don't have to perform a judgement; otherwise, we couldn't understand a sentence that we judge to be false. Understanding that $p$ is not judging that $p$. Yet, setting aside Meinong's argument, which conceives of assuming as a way of producing some articulated content, is there any objective reason to analyse understanding that $p$ in terms of assuming that $p$ ? On the face of it, understanding is not the same as assuming. Again, it seems that further distinctions are needed to do justice to the variety of cognitive attitudes. ${ }^{40}$

It seems to me that Difficulties 2.1-2.5 derive from a common source, namely: the claim (M3) that assuming that $p$ is best analysed in terms of affirming that $p$ or denying that $p$, as if an assumption would be but an incomplete judgement, a judgement lacking the belief component. We have seen how Meinong arrived at this analysis. The equivalences offered in M0-M3 are not introduced "under the pressure of the phenomena", so to speak. Rather, they are motivated by

\footnotetext{
${ }^{38}$ Reinach 1989b, p. 125.

${ }^{39}$ Reinach 1989a, p. 425.

${ }^{40}$ Richard 2017, p. 236-37.
} 
Meinong's view that there must be some activity involved in the apprehension of a higher-order object. Even if one agrees with this last claim, however, thinking of this apprehension as constitutively made up of an affirmative or negative attitudinal component common to judging and assuming proves highly problematic, for an affirmative or negative attitudinal component necessarily is committal - or it is not attitudinal after all, but merely contentual. Again, it is hard to see how the notions of affirming and denying might be understood in a both attitudinal and noncommittal sense. One main moral to be drawn from all that precisely is that assuming that $p$ cannot be construed as a committal attitude like judging that $p$.

To finish, I want now to sketch an alternative analysis. Drawing on suggestions made by Broad and - more recently - Kriegel, my proposal is to take entertaining that $p$ as a phenomenological primitive besides affirming that $p$.

\section{Entertaining as a Phenomenological Primitive}

Some authors have suggested that at least some assumptive experiences were to be analysed in terms of entertaining that $p$, to the effect that entertaining should be considered a phenomenological primitive. As far is I know, this suggestion first emerged in a review of Meinong's treatise on assumptions written by Stout's assistant, Charlie Broad. Broad writes:

I cannot help thinking that there are really three different attitudes towards a proposition and that Meinong confounds two of them under the name Annahme. These two I would distinguish as supposition and entertainment. It seems to me that entertainment clearly differs from supposition and is presupposed both by it and by judgement. When Meinong insists on the resemblance of Annahmen to judgement I think he has suppositions in mind; when he says that every judgement presupposed a corresponding Annahme I think he has entertainment in mind. But entertainment as distinct from supposition does not seem to me to differ from having an idea. ${ }^{41}$

Similarly, Twardowski, like Brentano, uses the notion of presentation and insists that what is presented when one understands a sentence is the judgement expressed by the sentence:

When someone maintains that Descartes lived in the 15th century, I perfectly understand this sentence; yet, since I take it that the judgement "Descartes lived in the 15th century" is false, it is plain that I cannot perform it. Here, therefore, the

${ }^{41}$ Broad 1913, p. 92. 
understanding of the sentence rests quite obviously on the presenting of the judgement denoted by the sentence; performing the judgement thus proves quite irrelevant for the understanding of the sentence. ${ }^{42}$

To this, Meinong would naturally object that an act of judging cannot properly speaking be the object of a presentation: "Am I at all able to think of X's judgement that $A$ is not $B$, if I do not in the first place somehow think that $A$ is not $B ? "{ }^{43}$ Still, even if we grant that some thinking is required here, nothing forces us to endorse (M1) Meinong's analysis of thinking in terms of judging or assuming, let alone (M3) his analysis of assuming in terms of affirming or denying. My own suggestion is that, from a merely attitudinal point of view, a more neutral attitude will do. This is precisely what is offered by Broad's analysis in terms of entertaining.

More recently, Uriah Kriegel proposed a similar analysis. He suggested that entertaining could be conceived of as a phenomenological primitive not unlike Brentano's neutral Vorstellen. Importantly, entertaining is an attitude which admits of a number of modifications. I can entertain a proposition in order to decide whether I should believe it or not. But I can also entertain something in a way which is "purely contemplative" and "with no doxastic business in mind". ${ }^{4}$ This attitudinal distinction, Kriegel suggests, may be captured by distinguishing between considering and contemplating. Used in a technical sense, considering and contemplating are modifications of entertaining:

(K1) $S$ considers $p$ iff (i) $S$ entertains that $p$ and (ii) $S$ has the project of figuring out whether $p$.

(K2) $S$ contemplates $p$ iff (i) $S$ entertains that $p$ and (ii) $S$ does not have the project of figuring out whether $p$.

Importantly, those subtle variations do not alter the neutrality which is constitutive of the phenomenology of entertaining. As Kriegel puts it, "entertaining is doxastically neutral on the truth (and goodness) of $p$ when performed both in an engaged and in a disengaged mode". ${ }^{45}$

On the face of it, $\mathrm{K} 1$ is close to assuming or "supposing." In the case of "supposing", however, there is a crucial difference:

Sometimes we entertain that $p$ not because we want to know whether $p$, but because we want to know whether $q$, that is, we are interested in the plausibility of

\footnotetext{
42 Twardowski 2017, p. 150.

${ }^{43}$ Meinong 1910, p. 118-19, 1977, p. 118-19, 1976, p. 88.

${ }^{44}$ Kriegel 2013a, p. 5, 2015b, p. 112.

${ }^{45}$ Kriegel 2013a, p. 6.
} 
some proposition, and our process for figuring out the plausibility of that proposition involves entertaining that $p$. This seems to be what happens when we suppose that $p .^{46}$

Accordingly, assuming or supposing that $p$ would be best analysed as follows:

(K3) S supposes that $p$ iff (i) $S$ entertains that $p$ and (ii) $S$ wants to know what is inferable from $p$.

To be sure, this analysis leaves a number of questions open. It is an open question, for example, whether entertaining that $p$ is a common component present in any cognitive attitude (judging that $p$, believing that $p$, and the like). For the present purpose, however, suffice it to say that, on the proposed analysis, assuming (or supposing) that $p$ does not involve affirming that $p$ or denying that $p$ as phenomal components. I take it that this is a crucial departure from Meinong's analysis. This is not to say, of course, that affirming that $p$ and denying that $p$ are not phenomenological primitives. Yet, they are not part of the analysans of assuming that $p$.

My own feeling is that such an alternative analysis avoids the abovementioned difficulties. It avoids Difficulty 2.1 , since it does not force assumptive attitudes into the yes-no opposition. It also avoids Difficulty 2.2, for it makes assumptive attitudes compatible with judgemental attitudes that are directed at the same objective in the same respect. Disregarding the entertaining component they might well be sharing, assuming that $p$ and judging that $p$ are different attitudes altogether. Similarly, it seems to me that the analysis in terms of entertaining prevents the problem of multiple assumptions (Difficulty 2.3) - as well as that of converse separability (Difficulty 2.4) - of arising in the first place. Consider, again, the following sentence: "Locke says that Descartes is mistaken in teaching that there are innate ideas." Since, on Meinong's analysis, understanding that $p$ involves assuming that $p$, anyone who understands this sentence would have to assume (affirm-without-believing) that there are innate ideas and to assume (affirm-without-believing) that accepting the existence of innate ideas is a mistake. The two affirmations are hardly compatible with one another. If, on the contrary, understanding that $p$ is analysed in terms of entertaining that $p$, there is no clash of affirmations involved in the understanding of the above-mentioned sentence. Entertaining that $p$ being a noncommittal attitude, there is no contradiction in entertaining (the thought) that there are innate ideas and entertaining (the thought) that the theory of innate ideas is mistaken at the same time. Last but not least, the analysis in terms of

${ }^{46}$ Kriegel 2015b, p. 113. 
entertaining and modifications thereof places us in the position of accounting for fine-grained attitudinal distinctions, including the distinctions between considering that $p$, contemplating that $p$ and assuming that $p$.

\section{Conclusion}

I have argued that Meinong's analysis of assumption fails to adequately account for the noncommittal character of the latter. One main advantage of the alternative approach in terms of entertaining is that, with the above-sketched distinctions in hand, we might be able to avoid Difficulties 2.1-2.4 and to account for some interesting descriptive differences touched upon in Difficulty 2.5. Another interesting consequence is that the discrimination of entertaining attitudes implies the reference to some epistemic goals, as obvious from K1-K3. As already suggested by $M 7$, wondering whether $p$ involves the desire of knowing whether $p$. This suggests that a full-blown analysis of cognitive attitudes should posit conative attitudes as part of the analysans (wanting, having the project of, etc.). Thus, exploring the connections between cognitive and conative attitudes would be a further route of enquiry. ${ }^{47}$

Arnaud Dewalque

University of Liège a.dewalque@uliege.be

\section{References}

Bayne, Tim / Montague, Michelle eds. (2014), Cognitive Phenomenology, Oxford - New York: Oxford University Press.

Brentano, Franz. (Ms. EL 80), “Logik. Unpublished Manuscript EL 80. Provisional Online Edition, Franz Brentano Archiv Graz", ed. by Robin D. Rollinger. http://gams.uni-

graz.at/archive/objects/context:bag/methods/sdef:Context/get?mode=logik. - (1956), Die Lehre vom richtigen Urteil, Bern: Francke.

- (1995a), Descriptive Psychology, Engl. transl. by Benito Müller, London:

Routledge.

- (1995b), Psychology from an Empirical Standpoint, Engl. transl. by Antos C.

Rancurello, D. B. Terrell, and Linda L. McAlister, London: Routledge. Breyer, Thiemo / Gutland, Christopher eds. (2015), Phenomenology of Thinking.

\footnotetext{
${ }^{47}$ This article is the revised version of a paper presented at the University of Urbino. I'm grateful to the audience there, and especially to Federico Boccaccini, Edoardo Lamedica, Denis Seron and Venanzio Raspa for helpful comments on a previous draft.
} 
Philosophical Investigations into the Character of Cognitive Experiences, New York - London: Routledge.

Broad, Charlie (1913), "Critical Notice of A. Meinong, Über Annahmen (Leipzig, 1910)", in: Mind 22 (n.s.), p. 90-102.

Dewalque, Arnaud (2014), "Phénoménologie autrichienne: le programme de Brentano", in: Austriaca 78, p. 69-88.

- (2016), “L'intentionnalité cognitive et ses modes: Reinach Critique de

Brentano", in: Philosophie 128, 1, p. 20-33.

- (2017), "Külpe on Cognitive Attitudes", in: Discipline Filosofiche 27, 2, p. 157176.

- (2018), "Natural Classes in Brentano's Psychology", in: Brentano Studien 16,

p. 107-138.

Frege, Gottlob (1891), Funktion und Begriff, Jena: Pohle.

Höfler, Alois (1894), Psychische Arbeit, Hamburg - Leipzig: Voss.

- (1930), Psychologie, $2^{\text {nd }}$ ed., vol. 1., Wien - Leipzig: Hölder - Pichler -

Tempsky.

Horgan, Terence E. / John Tienson (2002), "The Intentionality of Phenomenology and the Phenomenology of Intentionality", in: Philosophy of Mind. Classical and Contemporary Readings, ed. by David J. Chalmers, Oxford - New York: Oxford University Press, p. 520-33.

Husserl, Edmund (2002), Urteilstheorie. Vorlesung 1905 (= Husserliana

Materialien, Bd. 5), ed. by Elisabeth Schuhmann, Dordrecht: Kluwer. Kriegel, Uriah (2013a), "Entertaining as a Propositional Attitude: A Non-

Reductive Characterization", in: American Philosophical Quarterly 50, 1, p. 1-22.

- (2013b), "The Phenomenal Intentionality Research Program", in: Phenomenal

Intentionality, ed. by U. Kriegel, Oxford: Oxford University Press, p. 1-26.

- (2015a), "The Character of Cognitive Phenomenology", in: Phenomenology of

Thinking. Philosophical Investigations Into the Character of Cognitive

Experiences, ed. by Thiemo Breyer and Christopher Gutland, New York -

London: Routledge, p. 25-43.

- (2015b), The Varieties of Consciousness, Oxford: Oxford University Press.

Marty, Anton (1906), "Über Annahmen (Ein Kritischer Beitrag Zur Psychologie,

Namentlich Der Deskriptiven)", in: Zeitschrift für Psychologie und

Physiologie der Sinnesorgane 40, p. 1-54.

- (1908), Untersuchungen zur Grundlegung der allgemeinen Grammatik und

Sprachphilosophie, Halle: Niemeyer.

Meinong, Alexius (1902), Über Annahmen, $1^{\text {st }}$ ed., Leipzig: Barth.

- (1910), Über Annahmen, $2^{\text {nd }}$ ed., Leipzig: Barth.

- (1968), “Über emotionale Präsentation”, in: Gesamtausgabe, 3: Abhandlungen 
zur Werttheorie, Graz: Akademische Druck- u. Verlagsanstalt, p. 283-465. - (1976), On Assumptions, Engl. transl. by J. Heanue, Berkeley: University of California Press.

- (1977), Über Annahmen, in: Gesamtausgabe, 4, Graz: Akademische Druck- u. Verlagsanstalt, p. iii-xxv, 1-384.

Reinach, Adolf (1989a), "Einleitung in die Philosophie (1913)", in: Sämtliche Werke, 1, München: Philosophia Verlag, p. 369-514.

- (1989b), "Zur Theorie des negativen Urteils (1911)", in: Sämtliche Werke, 1, München: Philosophia Verlag, p. 95-140.

Richard, Sébastien (2017), "Marty against Meinong on Assumptions", in: Mind and Language - On the Philosophy of Anton Marty, ed. by Guillaume Fréchette and Hamid Taieb, Berlin: De Gruyter, p. 219-240.

Röck, Tina (2017), "Brentano's Methodology as a Path through the Divide: On Combining Phenomenological Descriptions and Logical Analysis", Axiomathes 27, 5, p. 475-489.

Russell, Bertrand (1904), "Meinong's Theory of Complexes and Assumptions (II)", Mind 13, 51 (n.s.), p. 336-354.

- (1910), "Knowledge by Acquaintance and Knowledge by Description",

Proceedings of the Aristotelian Society 11, p. 108-128.

- (1951), "Knowledge by Acquaintance and Knowledge by Description", in:

Mysticism and Logic, $2^{\text {nd }}$ ed., Totowa: Barnes \& Noble, p. 152-167.

- (2004), Mysticism and Logic, $3^{\text {rd }}$ ed., London: Routledge.

Smith, David Woodruff (2015), "Phenomenally Thinking about this Individual", in: Phenomenology of Thinking. Philosophical Investigations into the Character of Cognitive Experiences, ed. by Thiemo Breyer and Christopher Gutland, New York - London: Routledge, p. 62-76.

Stout, George (1896), Analytic Psychology, vol. 1, London: Swan Sonnenschein \& Co.

Twardowski, Kasimierz (2014), On Prejudices, Judgements and Other Topics in Philosophy, ed. by Anna Brożek and Jacek Jadacki, Amsterdam: Rodopi.

Twardowski, Kasimierz (2017), “Über begriffliche Vorstellungen”, in: Gesammelte Deutsche Werke, ed. by Anna Brożek, Jacek Jadacki, and Friedrich Stadler, Cham: Springer, p. 145-164.

Witasek, Stefan (1908), Grundlinien der Psychologie, Leipzig: Meiner. 